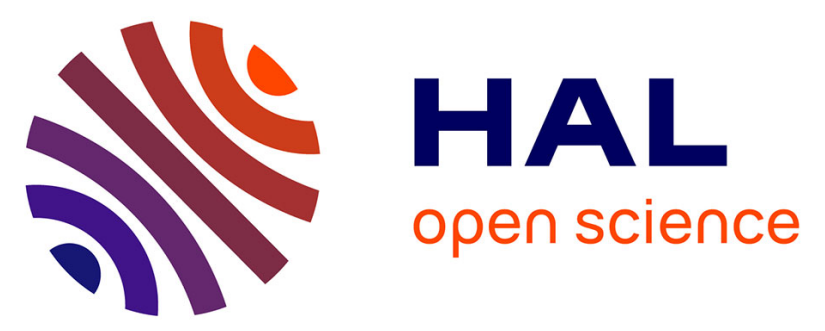

\title{
Control of an induction heat treatment by the measure of power
}

D. Meelab, Olivier Longeot, Laurent Krähenbühl, Laurent Nicolas, Philippe Wendling

\section{- To cite this version:}

D. Meelab, Olivier Longeot, Laurent Krähenbühl, Laurent Nicolas, Philippe Wendling. Control of an induction heat treatment by the measure of power. IEEE Transactions on Magnetics, 1993, 29 (2), pp.1558 - 1561. 10.1109/20.250701 . hal-00359845

\section{HAL Id: hal-00359845 https://hal.science/hal-00359845}

Submitted on 9 Feb 2009

HAL is a multi-disciplinary open access archive for the deposit and dissemination of scientific research documents, whether they are published or not. The documents may come from teaching and research institutions in France or abroad, or from public or private research centers.
L'archive ouverte pluridisciplinaire HAL, est destinée au dépôt et à la diffusion de documents scientifiques de niveau recherche, publiés ou non, émanant des établissements d'enseignement et de recherche français ou étrangers, des laboratoires publics ou privés. 


\title{
Control of an Induction Heat Treatment by the Measure of Power
}

\author{
D. Melaab, O. Longeot \\ ENSAM, LAMMAR, 33405 Bordeaux, France \\ L. Krähenbühl, L. Nicolas \\ LEL, ECL, 69131 Ecully, France \\ $\mathrm{Ph}$. Wendling \\ Magsoft Corporation, 1223 Peoples Avenue, Troy, NY 12180
}

\begin{abstract}
Heat treatment processes are commonly used to harden mechanical components. Among the most important problems encountered in this type of process are the reproducibility and control of the treatment. In this paper, we investigate a way to control induction heating processes through the measurement of the instantaneous active power transferred to the component. We first model the process using 2D and 3D CAD packages, then compare the results of the computation to the measurement of the power used in the actual process.
\end{abstract}

\section{INTRODUCTION}

Steel components of mechanical assemblies are hardened in order to increase their lifetime and durability. Induction heating is a very efficient way to heat the components [1].

For the treatment of long components, such as axles and gear shafts, coils that heat the component at once (single shot coils) are difficult to build and control. Scanning coils are preferred for heating long components. In such a process, a coil surrounds the component. The component is moved along the axis of the coil. A quenching device follows behind the coil, quenching that part of the component that was just heated. The heating stage is controlled by regulating both the power supplied to the coil and the linear velocity of the component passing through the coil [2].

To control the process, it is necessary to detect the beginning and the end of each component as it goes through the scanning coil. Also, to perform a uniform heat treatment, it is very important to detect precisely any irregularities in the geometry in order to regulate the power supplied to the coil.

This paper presents a method for detecting the changes in the shape of the component through electrical measurements performed on the coil. A computation was first performed to design and study the process. The results of the computation will be compared to measurements performed on the actual process.

\section{THE PROCESS}

The component is a gear shaft. Its shape is mainly cylindrical except for two notches machined on one side along an axis orthogonal to the axis of the cylinder. The goal of the process is to harden the material uniformly from under the surface towards the inside of the component, up to a constant depth of a few millimeters. The component is passed through a scanning coil and heated up to a temperature of at least $820^{\circ} \mathrm{C}$. After being pushed through the coil, the component is passed through a pressurized water spray. This spray performs the desired quenching. The distance between the coil and the water spray determines the holding stage. A schematic diagram of the process is shown in Figure 1. The geometry of the component is shown in Figure 2.

The component is made of stainless steel XC42 $(0.4 \%$
Carbon). In this paper, we will only investigate the heating stage of the process.

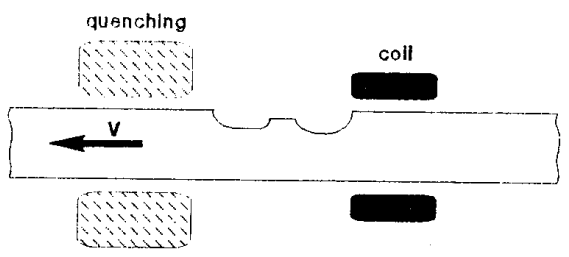

Fig. 1: Schematic diagram of the process

The method suggested to control the process is to measure the power supplied to the coil. Before the component starts going through the coil, the power dissipated is mainly reactive, except for the copper losses in the coil. When the component starts going through the coil, the active power increases. Similarly, when a change of shape in the geometry of the component goes through the coil, the active power increases or decreases because of the change occurring in the magnetic coupling between the coil and the component. By monitoring constantly the active power, it is possible to adjust both the power supplied to the coil and the velocity of the linear displacement of the component through the coil.

\section{The Modelling}

The frequency of the source used to heat the component is $10 \mathrm{kHz}$. The velocity of the linear displacement of the component through the coil does not exceed $0.03 \mathrm{~m} / \mathrm{s}$. The velocity does not create any extra eddy currents due to the motion effects.

Because of the temperature dependence of the magnetic and electrical properties of the material, the modelling of induction heat treatment requires proper accounting for magneto-thermal coupling. The thermal sources consist of the power dissipated by the eddy currents generated in the component being treated.

Because of the geometry of the component, the problem is three dimensional. However, the software tools available for solving coupled magneto-thermal problems have only two dimensional and axisymmetric capabilities. It was necessary to combine the use of a two dimensional $C A D$ package with the use of a three dimensional CAD package to compute the magnetic and thermal behavior of our process [3]. The 2D modelling helped to compute the different parameters of the heat treatment. The 3D modelling was performed to study the distribution of the power dissipated in the component versus the position of the coil. 


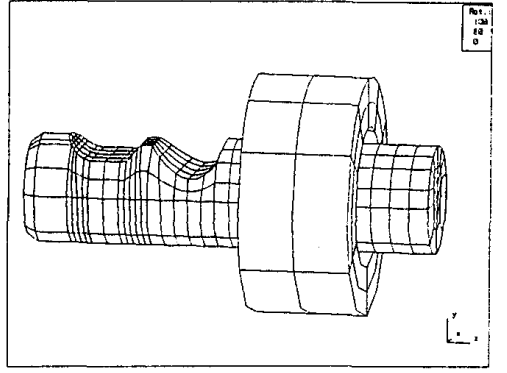

Fig. 2: Component and scanning coil (Phi3D)

A. Two dimensional FEM magneto-thermal modelling

Flux2D was used to perform the magneto-thermal modelling [4]. Flux2D features second order curvilinear elements. The program can compute non-linear steady state $A C$ problems coupled with non-linear transient thermal problems for two dimensional or axisymmetric geometries. For the steady state AC part of the problem, Flux $2 \mathrm{D}$ solves the following equation:

$$
j \omega \sigma A+\nabla_{x}\left((1 / \mu) x \nabla_{x(A))=-\sigma} \nabla(V) / 1\right.
$$

where $A$ is the vector potential (complex value), $J$ is the source term (complex value), $\omega$ is the angular frequency, $\mu$ is the magnetic permeability, $\sigma$ is the electric conductivity, 1 is the length of the coil and V is the voltage applied between the terminals of the coil.

Both $\sigma$ and $\mu$ depend on the temperature of the material. For the transient thermal part of the problem, Flux2D solves the following equation:

$$
\rho_{\mathrm{cp}}(\mathrm{dT} / \mathrm{dt})+\nabla_{\cdot(-\mathrm{k}} \nabla_{(\mathrm{T}))}=\mathrm{Q}
$$

where $\mathrm{T}$ is the temperature, $t$ is the time, $\rho_{\mathrm{cp}}$ is the specific heat, $k$ is the thermal conductivity and $Q$ is the thermal source (eddy current).

Both $\rho_{\mathrm{cp}}$ and $\mathrm{k}$ depend on the temperature of the material. To take into account the radiation and convection that occur during the heating phase, a non-homogeneous Neumann boundary condition is applied to the external border of the component:

$$
k(d T / d n)=-h\left(T-T_{a}\right)-\varepsilon \sigma\left(T^{4}-T_{a} 4\right)
$$

where $h$ is the convective exchange coefficient, $\varepsilon$ is the emissivity of the surface and $\sigma$ is the Stefan Boltzmann constant.

Here again, $h$ depends on the temperature of the surface. However, this temperature dependency is only needed to compute the cooling phase.

Flux2D first performs an initialization of the magnetic problem. This actually sets the thermal sources. Using an initial time step, Flux2D starts computing the thermal problem, iterating back on the magnetic problem to take into account the change in temperature. The results of both the electromagnetic and thermal problems are stored at the completion of each time step. After the computation of three time steps, a predictor - corrector algorithm adapts the time step to the variation of the electromagnetic and thermal phenomena.
Flux2D features an automatic mesh generator based on the Delaunay triangulation method and a semi-assisted mesh generator featuring both triangular and quadrangular elements. The semi-assisted mesh generator allows the user to control completely the mesh. The semi-assisted mesh generator was used to perform the meshing in order to insure a proper distribution of elements in the skin depth of the component and in the coil. The mesh of the thermal part of the problem is shown in Figure 3.

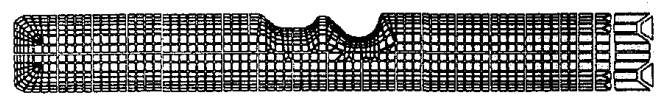

Fig. 3: Mesh in the component

Flux2D is an open program. Sources and material properties can be described using user developed subroutines. For our problem, we developed a subroutine to describe the electrical source and the resistivity of the source region. We defined a region of the domain representing the path of the coil (trace region) obtained when moving the coil along the component instead of moving the component through the coil. This region was considered as the source of the steady state $A C$ problem.

For computing the problem, we actually moved the coil instead of the component. A point of the region trace of the coil was either in the coil or in the vacuum at a given instant of the process. The user subroutines were used to compute the position of the coil at each time step, comparing the location of the points of the region trace to the position of the coil and energizing the points if found inside the coil at the current time step.

Another subroutine describes the water spray producing the quenching just behind the coil. The water spray and the coil were moving at the same velocity. Thus the three stages of the heat treatment, heating, holding and quenching, were included in the same problem. The results presented here show the three stages of the heat treatment but, in this paper, we will concentrate more on the heat cycle and its control.

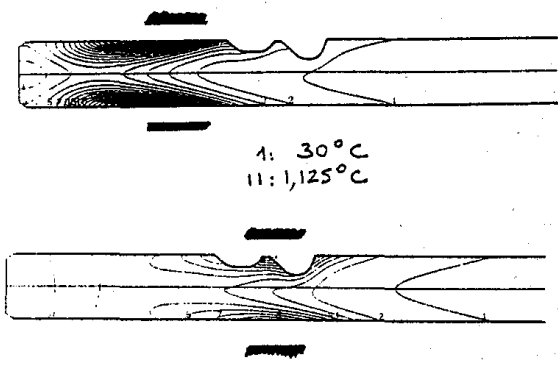

Fig. 4: Isothermal lines for 2 positions of the coil (Flux2D)

Figure 4 shows the isothermal lines for two positions of the coil: one before the notches on the gear shaft, the other one centered on the notches. Note that behind the coil, the hot zone is not at the surface of the region but inside, mainly because of the quenching.

Figure \#5 shows the variation of the temperature versus time at a test point, $1.25 \mathrm{~mm}$ below the surface of the component. We can check that the maximum temperature reached at this point exceeded $820^{\circ} \mathrm{C}$. We have achieved our 
objectives. The variation of the power dissipated inside the domain was also computed for comparison with the results of the three dimensional problem and with the measurements. The variation of the dissipated power versus the position of the coil is shown in Figure 6. However, we treated the problem as a two-dimensional problem (not even axisymmetric) and this curve is more qualitative than quantitative. Note that, as the coil moves over the notches, there is a drop in the active power dissipated in the component. We will check with a three dimensional modelling that this power drop has a magnitude large enough to be measured. Also, we need to check how precisely we can locate the notches from the reading of the power dissipated in the domain.

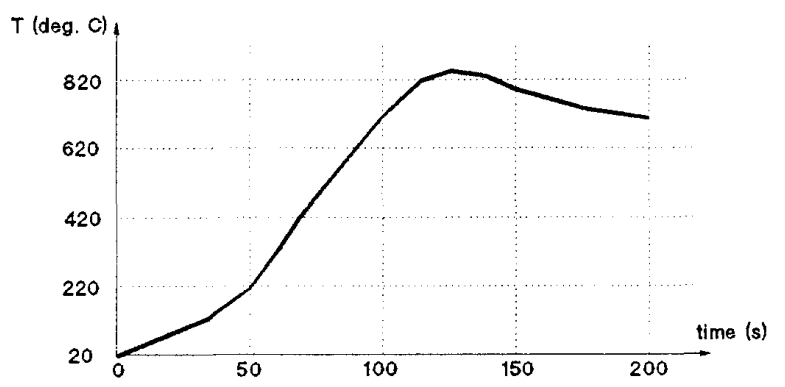

Fig. 5: Temperature vs. time at test point (Flux2D)

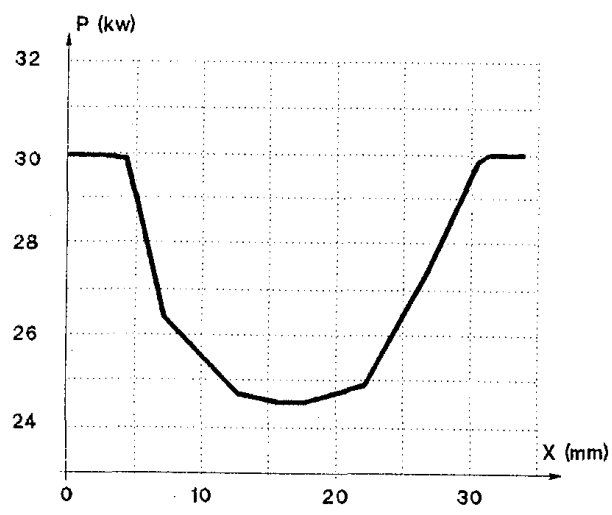

Fig. \#6: Power dissipated vs. position of the coil

$B$. Three dimensional $B E M$ high frequency $A C$ modelling

We model the actual three dimensional geometry using Phi3D [5]. Computations are made using a high frequency formulation described hereafter.

Our problem is to compute the magnetic field $\mathrm{H}$ through the air surrounding the conducting region (component to heat). In the air, a common way of proceeding is to break down the field $\mathrm{H}$ into two parts:

$\mathrm{H}_{\mathrm{o}}$ : the source field. This is the field due to the current of the coil exclusively. It is computed using the Biot-Savart law.

$\mathrm{H}_{\mathrm{i}}$ : the induced field. This field is due exclusively to the eddy currents. It is the gradient of a scalar potential $\phi$. We can then write: $\Delta V=0$ (Laplace's equation).

Work by Krähenbühl et al [6] shows that the Laplace equation is equivalent to the Boundary Integral Equation (B.I.E.):

$$
\phi(P)=-\int_{S}\left[\phi(Q) *\left[\delta G_{p}(Q) / \delta n\right]-[\delta \phi(Q) / \delta n]^{*} G_{p}(Q)\right] d s
$$

where $G$ represents the $3 D$ Green function, s represents the surface defining the air region (surface of the conductors) and $Q$ represents a point of integration located on the surface $s$.

For high frequency problems, the value of the skin depth is small compared to the dimensions of the conductors. We can assume that $\mathrm{H}$ is tangential to the surface of the conductors and constant. This leads to the following boundary condition [7]:

$$
\delta \phi / \delta \mathrm{n}=\mathrm{H}_{0} \cdot \mathrm{n}+((1-\mathrm{j}) / 2)^{*} \delta \mu_{\mathrm{r}}{ }^{*}\left(\nabla_{\mathrm{S}} \cdot \mathrm{H}-\Delta_{\mathrm{s}} \phi\right)
$$

where $n$ is the unit vector normal to the surface where the boundary condition is applied (surface of the conductor), $\delta$ is the skin depth and $\mu_{r}$ is the relative permeability of the conductor.

From the B.I.E., it is possible to compute $\phi$ and $H$ on the surfaces of the conductors and anywhere outside the conductors.

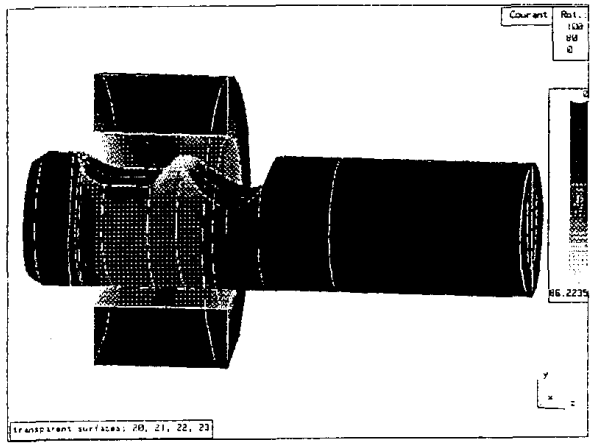

Fig. 7: Current distribution for one position of the coil

As the frequency approaches infinity, the value of the skin depth approaches 0 . The eddy currents flow only along the surfaces of the conductors. The conductors act as a perfect magnetic shield. There is no field inside the conductive regions. The boundary condition becomes (usually referred to as "the infinite frequency boundary condition"):

$$
\delta \mathrm{V} / \mathrm{\delta} \mathbf{n}=\mathrm{H}_{\mathrm{o}} \cdot \mathrm{n}
$$

The current density along the surface is:

$$
\mathrm{K}=\mathrm{H}_{\mathrm{otg}}-\nabla_{\mathrm{s} \phi}
$$

where $\mathrm{H}_{\mathrm{otg}}$ is the tangential component of the source field along the surfaces of the conductors. The active power dissipated in the conductor is:

$$
P=(1 / \delta s) \int_{S} H_{s t g} 2 d s
$$


where $\mathrm{H}_{\text {stg }}$ is the tangential component of the magnetic field along the surfaces of the conductors.

The current distribution along the surface of the axle and on the surface of the coil, resulting from the 3D computation, is shown in Figure 7. The shades of gray extend from black (no current), to almost white (maximum magnitude of current). Note that when the coil covers the tooth between the two notches, there is almost no power dissipated at the bottom of the notches. To heat the entire surface of the notches, we will have to slow down the motion of the component through the coil and/or move the coil to an offcenter position. The variation of the power dissipated versus the position of the coil is shown in Figure 8. The value of the power drops by $18 \%$ as it passes over the notches. Note that we cannot detect that there are actually two distinct notches. This is due to the size of the coil which is too wide compared to the size of the notches. A smaller coil would be able to pick up variations and locate the tooth between the notches.

These computations confirm what we predicted from the 2D analysis. The last part of our work was to build the device and measure the power dissipated inside the domain as a function of the position of the coil.

\section{THE EXPERIMENT}

To check the accuracy of what we computed by numerical modelling, we performed the actual heat treatment process of the gear shaft. The coil was moved at a velocity of $30 \mathrm{~mm} / \mathrm{s}$. Such a speed does not generate any appreciable eddy current due to the motional effects. The power supply delivered a constant voltage of $4.5 \mathrm{~V}$ at a frequency of $200 \mathrm{kHz}$ at the terminals of the coil. At $200 \mathrm{kHz}$ and $20^{\circ} \mathrm{C}$, the skin depth in the gear shaft is less than $1 \mathrm{~mm}$. The diameter of the shaft is $13 \mathrm{~mm}$.

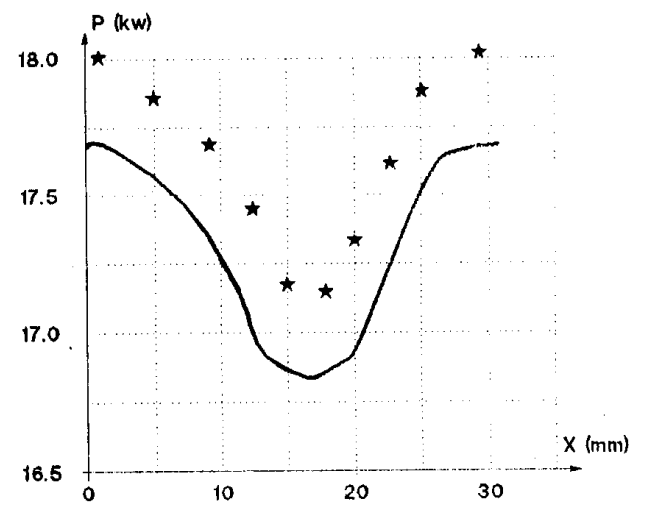

Fig. 8: Power vs. position - 3D modelling (--) and measurements (+)

The voltage at the terminal of the work coil (part of the coil surrounding the component only) and the current through the coil were measured using hardware specially developed for this type of process. The hardware includes a current transformer and a device for sampling the voltage and the current and computing the power [8]. The power was computed by integration:

$$
P_{a}=(1 / T) \int_{T} \text { uidt }
$$

where $T$ is the period of the source ( 1 /frequency), $u$ is the instantaneous value of the voltage and $i$ is the instantaneous value of the current.

The active power versus the position of the coil was recorded. Figure \#8 shows the two curves of variation of the active power versus the position of the coil for the 3D modelling and the experiment. The value of the power obtained through 3D modelling is slightly different from the measured power. This is due to the fact that in the experiment, we measured the power dissipated inside the full circuit and not only inside the component (gear shaft). However, the relative variation of the power when the coil goes over the notches is $4.8 \%$ when computed with the $3 D$ modelling, and $5 \%$ when measured. The measurement matched the results of the 3D modelling in general shape with a surprising precision.

\section{CONCLUSION}

We have shown how it is possible to solve complex modelling problems, in our case a three dimensional magnetothermal problem with a moving source, through the combined use of different modelling tools (2D Finite Element and 3D Boundary Element programs).

Measuring the active power transferred by the coil is an efficient way to detect changes in the shape of components being heat treated with a scanning coil. It gives accurate measurements and does not require any modification of the process itself. The measurement of power can be used to control the power supplied to the coil, the linear displacement of the component and eventually displacements of the coil for correcting the coupling.

\section{REFERENCES}

[1] O. Longeot, D. Durand, M. DeBortoli, and Ph. Wendling "How computer modelling helps design a heat treat process" Heat Treating, Volume XXII Number 6, pp. 21-26, June 1990

[2] Djamel Melaab "Amelioration de la qualite du traitement superficiel par induction, par controle an temps reel du transfert energetique entre la source de puissance et la charge" PhD thesis, ENSAM, Bordeaux, 1991

de puissance et la charge" $P h D$ thesis, ENSAM, Bordeaux, 1991
[3] O. Longeot, L. Nicolas and $\mathrm{Ph}$. Wendling "3D design of an inductor for [3] O. Longeot, L. Nicolas and $\mathrm{Ph}$. Wendling $3 \mathrm{D}$ design of an inductor for induction heating using 2D FEM and 3D Bagn., Volume 27 No. 5, pp.4004-4007, 1991

[4] "Flux2D user's guide" Magsoft Corporation, 1223 Peoples Avenue, Troy, NY 12180, 1992

[5] "Phi3D user's guide" Magsoft Corporation, 1992

6] L. Krähenbühl and A. Nicolas "Méthode des équations intégrales de 6] $\mathrm{L}$. Krähenbühl and $\mathrm{A}$. Nicolas "Méthode des équations intégrales de
frontiéres, développement des tachniques et formulations axisymétriques" R.G.E, March pp. 222-226, 1985

[7] L. Krähenbühl "Surface current and eddy-current 3D computation using Boundary Integral Equation Techniques" 3rd International Symposium IGTE, Graz, Austria, September 1988.

[8] "Energy sensor" CET 8702, SERTHEL/LAMMAR, 24, Avenue Pasteur, 77410 Claye-Souilly, France, Sepember 1991

Biography:

O. Longeot received his $\mathrm{Ph} . \mathrm{D}$ from "Ecole Nationale Supérieure des Arts et Métiers", Bordeaux, France in 1985 . He is a professor in the same University.

D. Melaab received his $\mathrm{Ph} . \mathrm{D}$ from "Ecole Nationale Supérieure des Arts et Métiers", Bordeaux, France in 1991. He has a post doc position in the same University.

L. KrähenbÜhl received his $\mathrm{PhD}$ from Ecole Centrale de Lyon, Lyon, France, in 1983. He occupies a research position in the "Department d'Electro-technique" of "Ecole Centrale De Lyon".

L. Nicolas received his Ph.D from Ecole Centrale De Lyon, Lyon, France in L. Nicolas received his Ph.D from Ecole Centrale De Lyon, Lyon, France in
1986 . He occupies a research position in the "Department d'Electrotechnique" of "Ecole Centrale De Lyon".

Ph. Wendling graduated as an engineer from "Institut Industriel du Nord", Lille, France in 1979. He currently is director of Marketing and Technical Support at Magsoft Corporation. 